\title{
60. ROCK MAGNETIC PROPERTIES OF SEDIMENTS FROM SITE 797, JAPAN SEA ${ }^{1}$
}

\author{
M. Torii, ${ }^{2}$ A. Hayashida, ${ }^{3}$ L. Vigliotti, ${ }^{4}$ and J. Wippern ${ }^{5}$
}

\begin{abstract}
Paleomagnetic and rock magnetic studies of the sediment samples from Site 797 were carried out. Thermal demagnetization was found to be more effective in removing secondary overprinting than alternating field demagnetization. Production of new magnetic minerals during the thermal treatment was frequently observed and made thorough demagnetization difficult, however. Thermal demagnetization of orthogonal IRM's suggests that magnetite and pyrrhotite are common magnetic minerals in these sediments. The Lowrie-Fuller test and $\chi_{\text {ARM } / \chi}$ ratio show apparent grain size of the magnetic minerals to be that of single-domain to small multi-domain state. A downcore decrease of rock magnetic parameters such as ARM, IRM, and $\chi$ ARM/ $\chi$ ratio in the upper half of the hole indicates progressive diagenetic dissolution of finer magnetic minerals. In the lower part where igneous rocks intruded, production of magnetic minerals is suggested by discontinuous change of the downcore trend, which may have brought remagnetization of the sediment samples.
\end{abstract}

\section{INTRODUCTION}

Paleomagnetic studies of deep-sea sediments have been carried out extensively during a series of deep sea drilling cruises from Deep Sea Drilling Project (DSDP) to Ocean Drilling Program (ODP). In order to provide reliable records of the ancient geomagnetic field, we need to carefully examine the reliability of the natural remanent magnetization (NRM) of sediments. Beside various arguments about the acquisition of detrital remanent magnetization, sediments go through quite complicated physical and/or chemical processes during diagenesis and lithification (e.g., King and Channell, 1991). These factors mean that the magnetic minerals might have been formed and/or undergone dissolution, thus causing a growth of secondary remanence. Careful rock magnetic examination is therefore indispensable for the study of sedimentary paleomagnetism. An optimum demagnetization treatment should be derived by a rock magnetic study including identification of magnetic minerals and estimation of their domain state.

Kobayashi and Nomura (1972) measured NRM's of piston core samples recovered from the central part of the Japan Basin, and they were not able to find any primary component of NRM. They attributed their unsuccessful attempts to the omnipresence of iron sulfides (pyrite and pyrrhotite). Paleomagnetic work was not successfully carried out in the previous DSDP cruise in the Japan Sea (Leg 31; Karig, Ingle, et al., 1975). Sediment samples recovered in Leg 127 show several characteristics such as dark/light color alternation and sudden increases in biogenic input (Tamaki, Pisciotto, Allan, et al., 1990). This suggests variable paleoenvironments in the Japan Sea, mainly due to a cyclic change of oxic to anoxic circulation of the seawater (Tada and lijima, this volume). We therefore anticipate difficulty in obtaining paleomagnetic results from the sediment samples of Leg 127 . The primary purpose of this study is to identify magnetic minerals in the sediments to help interpretation of the shipboard paleomagnetic results (Tamaki, Pisciotto, Allan, et al., 1990). We conducted thermal demagnetization and rock magnetic studies of the Leg 127 sediments. Our experiments were carried out on bulk samples. We did not make any kind of

'Tamaki, K., Suyehiro, K., Allan, J., McWilliams, M., et al., 1992. Proc. ODP, Sci. Results, 127/128, Pt. 2: College Station, TX (Ocean Drilling Program),

${ }^{2}$ Department of Geology and Mineralogy, Kyoto University, Kyoto 606-01, Japan.

${ }^{3}$ Laboratory of Earth Sciences, Doshisha University, Kyoto 602, Japan.

${ }_{5}^{4}$ Istituto di Geologia Marina, CNR, I-40127 Bologna, Italy.

${ }^{5}$ Institute Angewandte Geophysik, Universität München, D-8000 München, Federal Republic of Germany. magnetic separation and/or condensation of magnetic mineral. We thought that the magnetic separation may bias mineral identification by overestimating larger grains. And also the volume of our sample from each horizon is only $7 \mathrm{~cm}^{3}$ which is not enough for any practical kind of magnetic separation.

\section{SAMPLES AND LABORATORY PROCEDURE}

We collected cubic samples mainly from silt and clay layers of Site 797 (located in the northern part of the Yamato Basin); 11 sampling horizons were selected from the cores recovered by using Advanced Piston Corer (APC), 5 horizons from Extended Core Barrel (XCB), and 7 horizons from conventional Rotary Core Barrel (RCB). The selection of coring methods roughly reflect the degree of consolidation of sediments. The diagenetic change of biogenic silica in the sediments, which was accelerated by the increase of temperature and duration time of burial (Tada, 1991) is also a good indicator for showing physicochemical change in the sediments. Two distinct diagenetic boundaries were recognized in Site 797 sediments (Tamaki, Pisciotto, Allan, et al., 1990; Tada and Iijima, this volume). The opal-A zone to opal-CT zone transition occurs between 294.3 and $299.1 \mathrm{mbsf}$ and the opal-CT zone to quartz zone transition occurs between 428 and $438 \mathrm{mbsf}$. Unfortunately, there is only one sampling horizon from the opal-CT zone, but we collected enough samples from the opal-A and quartz zones.

From each horizon, we obtained two vertically adjacent samples. Six additional samples were obtained from the Brunhes-Matuyama transition zone (around $40 \mathrm{mbsf}$ ). Total numbers of studied samples are 52 from 29 horizons (Table 1). Those samples were kept in a magnetically shielded box until they dried at room temperature. Subsequently, the samples were removed from the ODP plastic containers, then marked and weighed. Remanent magnetization was measured using a two-axis cryogenic magnetometer (ScT C112) and a spinner magnetometer (Schonstedt SSM-1A).

The two adjacent samples were tested according to the following procedures: One of the paired samples was thermally demagnetized progressively up to $580^{\circ}$ or $610^{\circ} \mathrm{C}$ in $30^{\circ}-40^{\circ} \mathrm{C}$ steps. Thermal demagnetization was conducted using a non-inductive electric oven, in which the residual field was controlled to less than $5 \mathrm{nT}$ throughout the experiments. A four-layered cylindrical magnetic shield case with a demagnetizing coil was employed to maintain magnetic shielding of the oven. Initial susceptibility $(\chi)$ was measured using a Bartington M.S. 2 susceptibility meter at each step of the thermal treatment to detect thermochemical changes in the samples. 
Table 1. Rock magnetic properties of the sediments samples from Site 797.

\begin{tabular}{|c|c|c|c|c|c|c|c|c|c|c|c|c|c|}
\hline Sample & Depth & Color & Weight & $\chi$ & $\chi_{450} / \chi$ & Ber & ARM & $\mathrm{ARM}_{0.5}$ & $\chi_{\text {ARM }}$ & IRM & $\operatorname{IRM}_{0.5}$ & $\Delta \mathrm{LF}$ & Type \\
\hline $797 \mathrm{~B}-2 \mathrm{H}-3,68-70 \mathrm{~cm}$ & 9.59 & d & 5.38 & 0.85 & 5.3 & 50.8 & 1.54 & 23.9 & 1.94 & 2.45 & 20.0 & 3.9 & B \\
\hline $797 \mathrm{~B}-2 \mathrm{H}-3,70-72 \mathrm{~cm}$ & 9.61 & d & 4.44 & 0.92 & 1.8 & & & & & & & & \\
\hline $797 \mathrm{~B}-3 \mathrm{H}-3,34-36 \mathrm{~cm}$ & 18.75 & 1 & 3.45 & 1.12 & 2.1 & 63.0 & 2.44 & 25.9 & 3.07 & 6.06 & 25.6 & 0.3 & B \\
\hline $797 \mathrm{~B}-3 \mathrm{H}-3,36-38 \mathrm{~cm}$ & 18.77 & 1 & 3.17 & 0.96 & 2.3 & & & & & & & & \\
\hline $797 \mathrm{~B}-4 \mathrm{H}-3,141-143 \mathrm{~cm}$ & 29.32 & d & 4.08 & 0.69 & 14.0 & 45.8 & 2.87 & 20.0 & 3.61 & 4.37 & 17.9 & 2.1 & B \\
\hline $797 \mathrm{~B}-4 \mathrm{H}-3,144-146 \mathrm{~cm}$ & 29.35 & d & 3.73 & 0.75 & 7.7 & & & & & & & & \\
\hline $797 \mathrm{~B}-5 \mathrm{H}-4,39-41 \mathrm{~cm}$ & 39.30 & 1 & 4.46 & 0.74 & 1.6 & 63.1 & 1.22 & 25.4 & 1.53 & 2.15 & 22.6 & 2.8 & B \\
\hline 797B-5H-5, 138-140 cm & 41.79 & 1 & 3.68 & 0.97 & 1.9 & 63.3 & 1.98 & 27.5 & 2.49 & 3.72 & 23.1 & 4.9 & B \\
\hline 797B-5H-5, $140-142 \mathrm{~cm}$ & 41.81 & 1 & 3.80 & 0.92 & 1.6 & & & & & & & & \\
\hline 797B-5H-6, 105-107 cm & 42.92 & d & 4.49 & 0.71 & 9.9 & 56.3 & 1.54 & 24.6 & 1.94 & 2.22 & 22.0 & 2.6 & B \\
\hline $797 \mathrm{~B}-6 \mathrm{H}-2,24-26 \mathrm{~cm}$ & 47.15 & 1 & 4.46 & 0.95 & 4.7 & 53.5 & 1.74 & 25.1 & 2.18 & 4.28 & 23.0 & 2.1 & B \\
\hline $797 \mathrm{~B}-6 \mathrm{H}-3,54-56 \mathrm{~cm}$ & 48.95 & d & 5.94 & 0.70 & 6.0 & 62.0 & 1.24 & 24.6 & 1.56 & 1.97 & 22.5 & 2.1 & B \\
\hline $797 \mathrm{~B}-6 \mathrm{H}-5,83-85 \mathrm{~cm}$ & 50.74 & d & 4.60 & 0.95 & 5.4 & & & & & & & & \\
\hline $797 \mathrm{~B}-6 \mathrm{H}-5,85-87 \mathrm{~cm}$ & 50.76 & d & 4.17 & 0.75 & 7.1 & 56.9 & 1.27 & 26.8 & 1.60 & 2.39 & 23.9 & 2.9 & B \\
\hline $797 \mathrm{~B}-6 \mathrm{H}-5,94-96 \mathrm{~cm}$ & 50.85 & d & 5.11 & 0.83 & 1.8 & 73.4 & 1.49 & 27.8 & 1.88 & 2.90 & 26.1 & 1.7 & B \\
\hline $797 \mathrm{~B}-6 \mathrm{H}-6,95-97 \mathrm{~cm}$ & 52.36 & 1 & 6.74 & 0.99 & 3.1 & 71.9 & 1.68 & 28.2 & 2.12 & 6.29 & 33.8 & -5.6 & A \\
\hline $797 \mathrm{~B}-8 \mathrm{H}-5,88-90 \mathrm{~cm}$ & 69.79 & 1 & 3.46 & 1.09 & 1.5 & 57.4 & 1.73 & 25.6 & 2.18 & 3.01 & 19.8 & 5.8 & B \\
\hline $797 \mathrm{~B}-8 \mathrm{H}-5,90-92 \mathrm{~cm}$ & 69.81 & i & 3.00 & 1.06 & 1.2 & & & & & & & & \\
\hline $797 \mathrm{~B}-10 \mathrm{H}-5,61-63 \mathrm{~cm}$ & 88.52 & d & 5.15 & 1.30 & 1.8 & & & & & & & & \\
\hline $797 \mathrm{~B}-10 \mathrm{H}-5,63-65 \mathrm{~cm}$ & 88.54 & d & 5.49 & 1.15 & 1.6 & 50.1 & 1.17 & 24.3 & 1.47 & 1.95 & 18.9 & 5.4 & B \\
\hline $797 \mathrm{~B}-12 \mathrm{H}-3,61-63 \mathrm{~cm}$ & 105.52 & 1 & 2.55 & 0.68 & 9.3 & 62.0 & 0.92 & 26.3 & 1.15 & 1.62 & 23.5 & 2.8 & B \\
\hline 797B-12H-3, 64-66 cm & 104.55 & 1 & 3.54 & 0.85 & 7.2 & & & & & & & & \\
\hline 797B-13H-2, 12-14 cm & 113.03 & $\mathrm{~s}$ & 4.50 & 1.44 & & 67.9 & 3.03 & 27.5 & 3.81 & 7.26 & 24.1 & 3.4 & \\
\hline $797 \mathrm{~B}-13 \mathrm{H}-2,14-16 \mathrm{~cm}$ & 113.05 & s & 3.59 & 3.69 & & & & & & & & & \\
\hline 797B-15H-4, 61-63 cm & 134.52 & 1 & 3.55 & 0.95 & 1.9 & 62.0 & 1.02 & 26.1 & 1.28 & 1.68 & 25.6 & 0.5 & B \\
\hline $797 \mathrm{~B}-15 \mathrm{H}-4,64-66 \mathrm{~cm}$ & 134.55 & 1 & 3.59 & 0.89 & 2.5 & & & & & & & & \\
\hline $797 \mathrm{~B}-19 \mathrm{H}-2,113-115 \mathrm{~cm}$ & 169.04 & 1 & 3.39 & 0.69 & 5.0 & & & & & & & & \\
\hline $797 \mathrm{~B}-19 \mathrm{H}-2,115-117 \mathrm{~cm}$ & 169.06 & 1 & 2.69 & 0.61 & 4.8 & 52.7 & 0.75 & 24.8 & 0.94 & 1.13 & 20.0 & 4.8 & B \\
\hline $797 \mathrm{~B}-24 \mathrm{X}-4,12-14 \mathrm{~cm}$ & 218.93 & & 2.18 & 1.77 & 5.1 & 44.2 & 0.73 & 24.4 & 0.92 & 1.19 & 16.1 & 8.3 & B \\
\hline $797 \mathrm{~B}-24 \mathrm{X}-4,14-16 \mathrm{~cm}$ & 218.95 & & 2.94 & 0.36 & & & & & & & & & \\
\hline 797B-28X-4, 7-9 cm & 257.68 & & 2.73 & 3.23 & 1.8 & 43.0 & 1.04 & 24.7 & 1.30 & 1.13 & 17.2 & 7.5 & $\mathrm{C}$ \\
\hline 797B-28X-4, 9-11 cm & 257.70 & & 3.19 & 2.58 & 2.4 & & & & & & & & \\
\hline \multicolumn{14}{|c|}{ Opal-A and Opal-CT boundary } \\
\hline $797 \mathrm{~B}-34 \mathrm{X}-3,10-12 \mathrm{~cm}$ & 314.31 & & 6.15 & 0.93 & 1.9 & & & & & & & & \\
\hline $797 \mathrm{~B}-34 \mathrm{X}-3,17-19 \mathrm{~cm}$ & 314.38 & & 5.23 & 1.00 & 2.5 & 49.0 & 1.85 & 26.4 & 2.32 & 1.90 & 21.1 & 1.4 & C \\
\hline \multicolumn{14}{|c|}{ Opal-CT and Quartz boundary } \\
\hline 797B-47X-5, $116-118 \mathrm{~cm}$ & 443.37 & & 9.14 & 0.30 & 11.0 & 41.6 & 0.57 & 23.7 & 0.71 & 0.53 & 17.6 & 6.1 & $\mathrm{C}$ \\
\hline $797 \mathrm{~B}-47 \mathrm{X}-5,118-120 \mathrm{~cm}$ & 443.39 & & 8.67 & 0.28 & 9.6 & & & & & & & & \\
\hline 797B-51X-3, 74-76 cm & 478.65 & & 8.48 & 0.34 & 16.0 & & & & & & & & \\
\hline $797 \mathrm{~B}-51 \mathrm{IX}-3,76-78 \mathrm{~cm}$ & 478.67 & & 7.06 & 0.38 & 9.6 & 37.4 & 0.58 & 21.5 & 0.73 & 1.09 & 15.9 & 5.6 & C \\
\hline $797 \mathrm{C}-3 \mathrm{R}-2,99-101 \mathrm{~cm}$ & 505.50 & & 7.82 & 1.02 & 2.2 & 39.0 & 2.63 & 24.3 & 3.30 & 3.51 & 15.7 & 8.6 & B \\
\hline $797 \mathrm{C}-3 \mathrm{R}-2,101-103 \mathrm{~cm}$ & 505.52 & & 8.90 & 0.91 & 2.2 & & & & & & & & \\
\hline $797 \mathrm{C}-6 \mathrm{R}-3,56-58 \mathrm{~cm}$ & 535.17 & & 9.18 & 3.53 & 0.9 & & & & & & & & \\
\hline $797 \mathrm{C}-6 \mathrm{R}-3,59-61 \mathrm{~cm}$ & 535.20 & & 7.12 & 3.47 & 1.0 & 41.5 & 1.18 & 23.3 & 14.80 & 44.50 & 10.9 & 12.4 & C \\
\hline $797 \mathrm{C}-22 \mathrm{R}-4,33-35 \mathrm{~cm}$ & 689.88 & & 10.70 & 1.02 & 0.9 & 34.8 & 2.05 & 23.1 & 2.57 & 3.90 & 11.0 & 12.1 & \\
\hline $797 \mathrm{C}-22 \mathrm{R}-4,35-37 \mathrm{~cm}$ & 689.90 & & 11.00 & 0.97 & 1.1 & & & & & & & & \\
\hline $797 \mathrm{C}-23 \mathrm{R}-3,33-35 \mathrm{~cm}$ & 697.94 & & 11.00 & 1.34 & 2.0 & & & & & & & & \\
\hline 797C-23R-3, 35-37 cm & 697.96 & & 10.73 & 1.23 & 0.9 & 34.0 & 2.35 & 22.5 & 2.95 & 3.73 & 11.9 & 10.6 & D \\
\hline $797 \mathrm{C}-25 \mathrm{R}-3,26-28 \mathrm{~cm}$ & 716.87 & & 10.80 & 2.98 & 1.2 & 34.0 & 6.24 & 23.2 & 7.84 & 16.30 & 9.9 & 13.3 & C \\
\hline $797 \mathrm{C}-25 \mathrm{R}-3,28-30 \mathrm{~cm}$ & 716.89 & & 12.30 & 2.36 & 1.0 & & & & & & & & \\
\hline $797 \mathrm{C}-34 \mathrm{R}-5,14-16 \mathrm{~cm}$ & 796.87 & & 12.00 & 0.98 & 1.4 & & & & & & & & \\
\hline $797 \mathrm{C}-34 \mathrm{R}-5,16-18 \mathrm{~cm}$ & 796.89 & & 11.97 & 1.12 & 1.5 & 34.2 & 1.00 & 23.1 & 1.25 & 1.33 & 12.7 & 10.4 & D \\
\hline $797 \mathrm{C}-37 \mathrm{R}-3,79-81 \mathrm{~cm}$ & 818.20 & & 12.00 & 0.52 & 1.5 & 42.0 & 1.88 & 26.2 & 2.36 & 2.06 & 18.4 & 7.8 & D \\
\hline $797 \mathrm{C}-37 \mathrm{R}-3,81-83 \mathrm{~cm}$ & 818.22 & & 10.90 & 0.50 & 2.3 & & & & & & & & \\
\hline
\end{tabular}

Depth $=$ meters below seafloor. Color $=(\mathrm{l})$ and $(\mathrm{d})$ indicate light and dark layers in APC samples, and $(\mathrm{s})$ indicates sands. Weight $=\mathrm{dry}$ weight in gram. $\chi=\mathrm{initial}$ susceptibility $\left(\times 10^{-7} \mathrm{~m}^{3} / \mathrm{kg}\right) \cdot \chi_{450} / \chi=$ ratio of initial susceptibility measured at $450^{\circ} \mathrm{C}$ to the value at room temperature. Bcr $=$ remanent acquisition coercivity in mT. ARM $=$ intensity

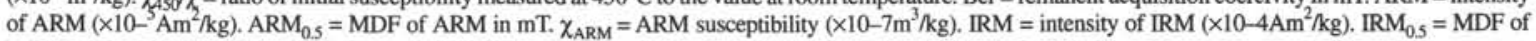
IRM in mT. $\triangle \mathrm{LF}=\mathrm{ARM}_{05}-\mathrm{IRM}_{05}$. Type = type of thermal demagnetization curve of orthogonal IRM's defined in Figure 5.

The other sample was subjected to the series of rock magnetic experiments. The sample was first demagnetized by the alternating field (AF) up to $100 \mathrm{mT}$ (peak field). AF demagnetization was carried out using a laboratory-made demagnetizer, which is a combination of $\mathrm{AF}$ oscillator and $\mathrm{AC}$ power amplifier, equipped with a three-layered magnetic shield case and a three-axis tumbler. Anhysteretic remanent magnetization (ARM) was then imparted to the sample at $100 \mathrm{mT}$ AF field biased by $0.1 \mathrm{mT}$ direct field, and followed by the progressive AF demagnetization. Isothermal remanent magnetization (IRM) was given to the demagnetized sample at $1.3 \mathrm{~T}$ parallel to $\mathrm{x}$ direction of the sample and then progressive IRM was applied to $-\mathrm{x}$ direction by incremental steps, which enables us to estimate remanent acquisition coercivity (Bcr). The sample was given nearly saturated IRM and then progressively AF demagnetized. These procedures allowed determination of the mass-specific ARM acquired per unit of direct field $\left(\chi_{\text {ARM }}\right)$, and also application of the modified Lowrie-Fuller test (Johnson et al., 1975), which bear rough estimation of the domain state of magnetic minerals. As the maximum field of the AF demagnetizer is $100 \mathrm{mT}$, nearly saturated IRM was not reduced to zero for most samples. Therefore, we subtracted the remaining IRM (after $100 \mathrm{mT}$ $\mathrm{AF}$ demagnetization) and normalized the demagnetization curve to obtain "corrected" median destructive field (MDF) of IRM following the method by Karlin (1990b). In order to make a quantitative evaluation of the Lowrie-Fuller test, we used a parameter DLF = (MDF of ARM) - (MDF of IRM) (Petersen et al., 1986). A positive but nearly zero value of $\triangle \mathrm{LF}$ indicates dominance of magnetic grains 
in single-domain (SD) state and pseudo-single-domain (PSD) state. Contrary to this, a negative value implies dominance of multi-domain (MD) grains. Larger positive values are thought to indicate mixture of SD/PSD and MD grains (Dunlop, 1983).

Finally, three orthogonally composite IRM's $(1.3 \mathrm{~T}$ to $\mathrm{z}$-axis = hard IRM, 0.4 T to $y$-axis = medium IRM, and $0.12 \mathrm{~T}$ to $\mathrm{x}$-axis $=\mathrm{soft}$ IRM) was imposed on the sample and followed by the progressive thermal demagnetization. This procedure reveals unblocking spectrum of three different ranges of coercivity, i.e., $0-0.12 \mathrm{~T}, 0.12-0.4 \mathrm{~T}$, and $0.4-1.3 \mathrm{~T}$. The soft IRM typically corresponds to magnetite, medium IRM to pyrrhotite, and hard IRM to hematite or goethite (Lowrie, 1990). Thermal demagnetization of IRM is particularly effective in identifying magnetic minerals in sediments which generally have very low concentration of magnetic materials. Curie temperature was measured for small piece of each sample by using a thermomagnetic balance.

\section{RESULTS AND DISCUSSION}

\section{Demagnetization}

During progressive AF demagnetization, most samples acquired an ARM at demagnetization levels between 30 and $50 \mathrm{mT}$ (Fig. 1). Only a few samples were not impaired by ARM. As shown by this unsuccessful attempt at AF demagnetization, it is difficult to determine the remanent polarity through the $\mathrm{AF}$ method alone.

We observed a stable high-temperature component, or a change in the sign of inclination from positive to negative, which indicates removal of a normal polarity secondary remanence. The examples are shown for samples $127-797 \mathrm{~B}-3 \mathrm{H}-3,36-38 \mathrm{~cm}, 127-797 \mathrm{~B}-4 \mathrm{H}-3$, 144-146 cm, 127-797B-5H-5, 140-142 cm, 127-797B-8H-5, 90-92 $\mathrm{cm}, 127-797 \mathrm{~B}-34 \mathrm{X}-3,10-12 \mathrm{~cm}$, and 127-797C-6R-3, 56-58 cm (Fig. 2). Thermal demagnetization, however, often showed a confusing pattern in the vector-demagnetization diagrams (Zijderveld, 1967) at temperatures higher than $300^{\circ} \mathrm{C}$. Samples 127-797B-6H-5, 83-85 $\mathrm{cm}$, and $127-797 \mathrm{~B}-12 \mathrm{H}-3,64-66 \mathrm{~cm}$, are examples of this behavior (Fig. 2). This pattern corresponds to an increase in initial susceptibility measured right after the thermal treatment (Fig. 3). In order to express the increase of initial susceptibility, we use the ratio of the value at $450^{\circ} \mathrm{C}$ to the value before demagnetization $\left(\chi_{450 /} \chi\right)$. As indicated in Figure 2, samples of larger $\chi_{450} \chi \chi$ ratio tend to display an irregular pattern in the vector-demagnetization diagrams.

The hump at about $450^{\circ} \mathrm{C}$ in curves of thermal change of susceptibility (Fig. 3) can be explained by production of new magnetic minerals during heating. In the upper $100 \mathrm{~m}$ of APC zone, the cyclic change of dark and light color alternation is one of pronounced sedimentary characters (Tamaki, Pisciotto, Allan, et al., 1990). There is, however, no relationship between the $\chi_{450} / \chi$ ratio and the color variation of the sediments (Fig. 3). Thermomagnetic curves also suggest the production of new magnetic minerals when heated in air. As typically shown in Figure 4, the strong-field magnetization of the bulk sample decays rather monotonically (showing paramagnetic curve) up to $350^{\circ} \mathrm{C}$. There is a sudden increase between $350^{\circ}$ to $500^{\circ} \mathrm{C}$ which decrease to 0 by about $600^{\circ} \mathrm{C}$. Upon cooling the curve is irreversible. These results may indicate the production of pure magnetite from non-magnetic minerals by the heating in the air. Although the thermal demagnetization is more effective than AF method, it is difficult to reveal high temperature remanent component for all of samples. The main difficulty in the thermal demagnetization is brought by laboratory produced magnetite during heating experiment.

\section{Magnetic Minerals}

Rock magnetic properties are basically controlled by magnetic mineralogy and domain state. First, we will discuss identification of magnetic minerals on the basis of the orthogonal IRM experiment. In Figure 5, we show four typical examples (type A to type D) of thermal demagnetization of orthogonal IRM's. Soft and medium
IRM curves of type A (127-797B-6H-06, 95-97 cm; $52.36 \mathrm{mbsf}$, from light color layer) show single unblocking temperature lower than $300^{\circ} \mathrm{C}$. This fact suggests the presence of magnetic minerals of moderate unblocking temperature and medium coercivity. Judging from its medium coercivity, the magnetic mineral is possibly pyrrhotite. The unblocking temperature is, however, somewhat lower than that of common pyrrhotite $\left(\mathrm{Fe}_{7} \mathrm{~S}_{8}\right)$. The magnetic mineral may be more iron-rich mineral such as $\mathrm{Fe}_{9} \mathrm{~S}_{10}$ (Tc is about $260^{\circ} \mathrm{C}$; O'Reilly, 1984). Throughout the study we found only one sample showing type A demagnetization curve. Although type B shows unblocking temperature lower than $300^{\circ} \mathrm{C}$, it also indicates higher unblocking temperature close to that of magnetite. We think this type of magnetic mineral is a mixture of pyrrhotite and magnetite. This type of IRM curves is the most popular in this site. Variation of the demagnetization curves may be controlled by the degree of mixture of pyrrhotite and magnetite. Type B samples are found both in the dark and light color layers of the APC sediments. Although such a color variation may reflect changes in depositional environment, we did not find significant correlation between sediment color and the orthogonal IRM property. Type $\mathrm{C}$ is characterized by less prominent medium IRM, which may indicate little contribution of pyrrhotite. Quick and smooth decay of the soft IRM curve in the lower temperature range may be attributable to multi-domain (titano)magnetite or presence of (titano)maghemite. Type D, pure magnetite, is a less common example and found only from deeper part where the sediment are sandwiched between igneous rocks. The classification of the orthogonal IRM property is listed in Table 1.

As already shown in Figure 4, most of the thermomagnetic curves show only paramagnetic decay in the low temperature range and not enough sensitive to reveal ferromagnetic component below $300^{\circ} \mathrm{C}$. The thermomagnetic curves were all irreversible when heated above $200^{\circ} \mathrm{C}$ or so. Although the thermomagnetic analysis is one of the best established method in rock magnetism, it was not effective in identifying magnetic minerals in this study.

\section{Grain Size of Magnetic Minerals}

The grain size distribution is one of the key parameters that control the stability of remanence. There are wide variations of methods to estimate the grain size or domain state of ferromagnetic minerals in sediments (e.g., Yamazaki and Katsura, 1990). Except for observation under a microscope, all grain size estimation methods are indirect. We tried the Lowrie-Fuller test and also made a comparison between anhysteretic susceptibility $\left(\chi_{\text {ARM }}\right)$ and initial susceptibility $(\chi)$, which was proposed by Banerjee et al. (1981) and King et al. (1982) as a magnetic granulometry technique. Unambiguous application of these methods require the identification of the magnetic minerals. When sediments contain a mixture of several magnetic minerals, the results may just give an apparent distribution of grain size. As shown in the previous section, the orthogonal IRM results suggested minor contribution from pyrrhotite in the case of type B, most dominant type in the opal A zone. In spite of complex mineral compositions, the Lowrie-Fuller test and the $\chi_{\text {ARM } /} \chi$ ratio may identify the apparent domain state of the dominant magnetic minerals in each sample.

Figure 6A shows the relationship between the MDF of IRM and $\triangle \mathrm{LF}$ determined for the Site 797 samples, which indicates a linear, negative correlation between the two factors. A negative correlation is also observed when $\Delta \mathrm{LF}$ is plotted against remanent acquisition coercivity (Bcr) as shown in Figure $6 \mathrm{~B}$. The value of $\triangle \mathrm{LF}$ is all positive and less than 15 except for one negative sample which is assumed to be dominated by pyrrhotite as shown in Figure 5 (type A; 127-797B-6H, 95-97 cm). Petersen et al. (1986) interpreted the negative correlation between the MDF of IRM and $\triangle \mathrm{LF}$ found in the DSDP Leg 73 samples (South Atlantic). The variation of $\triangle \mathrm{LF}$ and MDF of IRM observed in this study falls in a similar range to that of set B of Leg 73 (Petersen et al., 1986) that was identified as detrital titanomagnetite by observation under a scanning electron micro- 

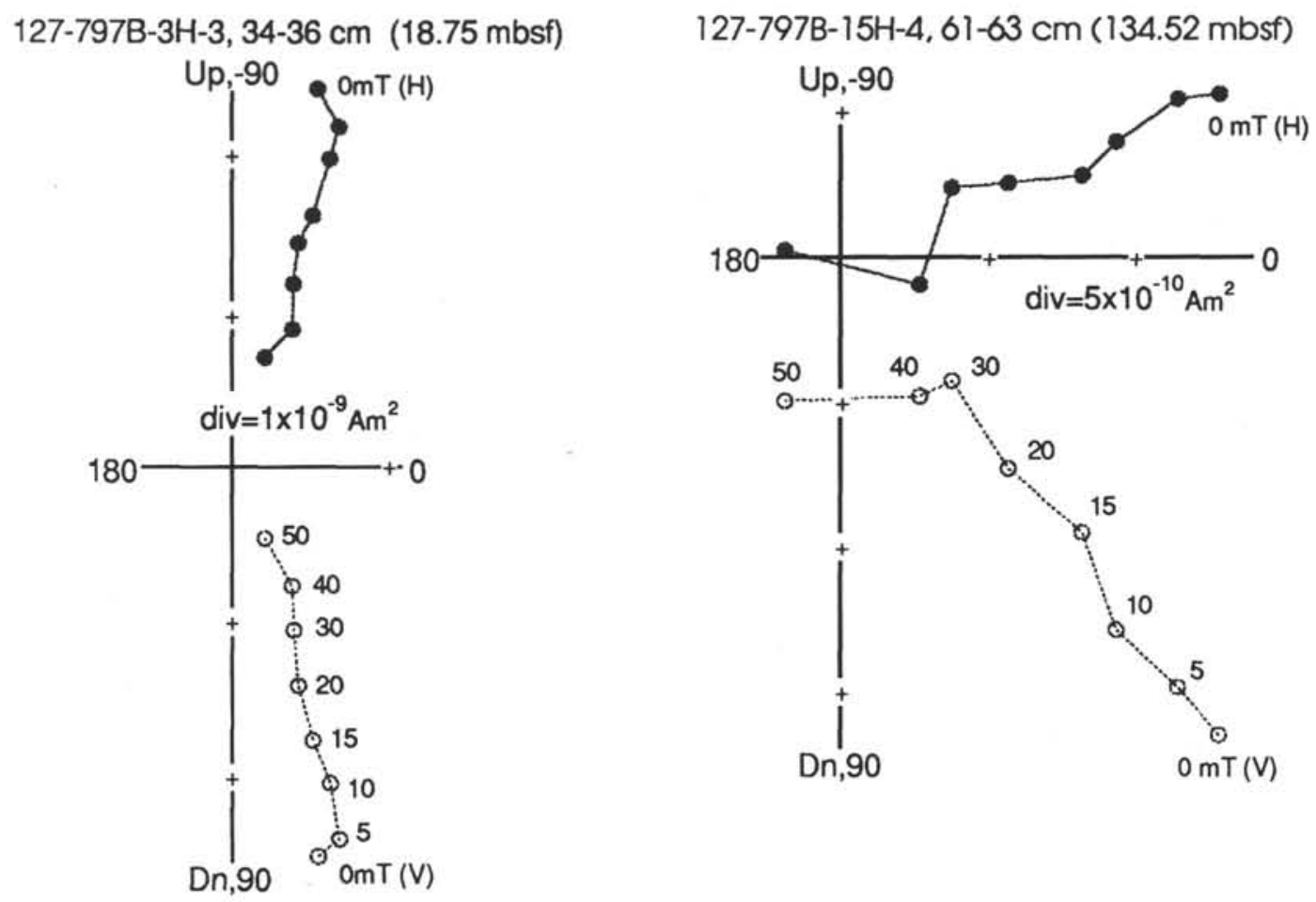

\section{$127-797 \mathrm{~B}-34 \mathrm{X}-3,17-19(314.38 \mathrm{mbsf})$}

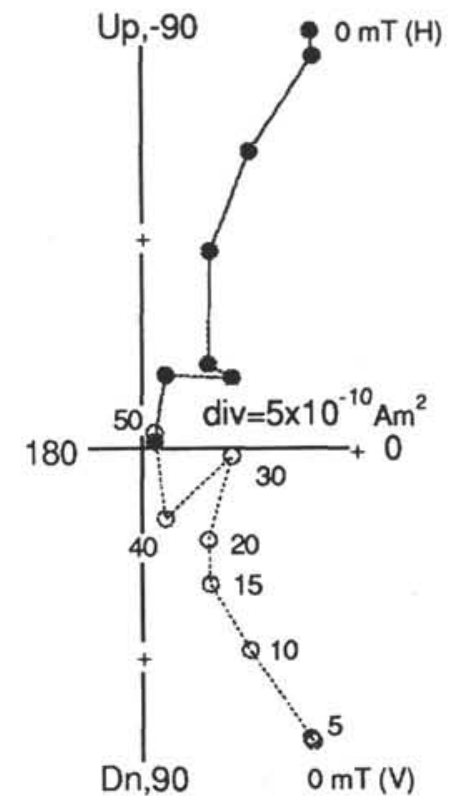

127-797C-37R-3, 79-81 cm (818.20 mbsf)

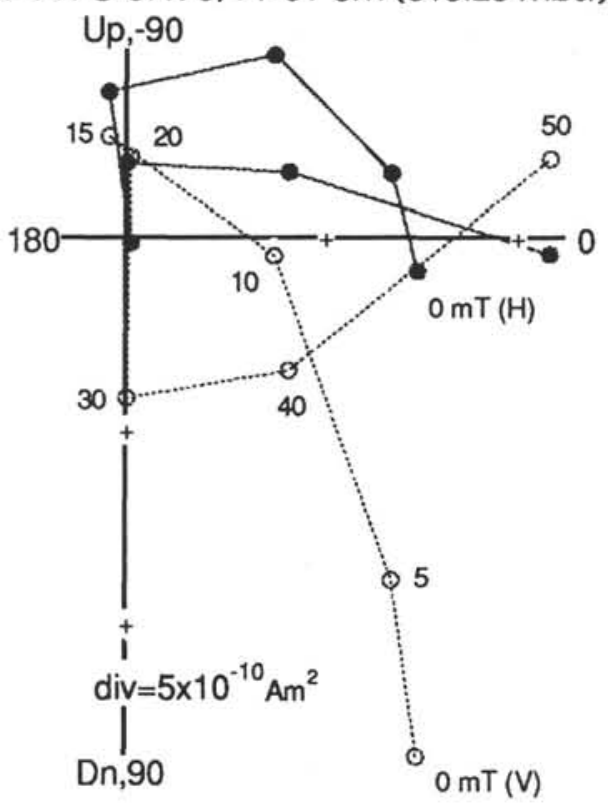

Figure 1. Examples of vector-demagnetization diagrams of stepwise AF demagnetization data. The peak field in $\mathrm{mT}$ is given for each point. Open and solid symbols indicate projection on vertical and horizontal planes, respectively. Up and Dn indicate upward and downward direction of the core, respectively. Azimuthal angle is arbitrary ("0" is perpendicular to the split surface of working-half of the core). "Div" refers to the bulk moment of each division of axes marked by ticks.

scope. Deep-sea sediments recovered from the Northeast Pacific show almost the same variation of $\triangle L F$ value (Karlin, 1990b). Except for one sample (type A), the variation of $\triangle \mathrm{LF}$ observed in Figure $6 \mathrm{~A}$ may suggest dominance of SD/PSD magnetic minerals within our samples. Although the data point plotted on Figure 6 showing a linear trend, they also make two clusters along the line, that is, sample from the opal-A zone and from the quartz zone. Open symbols (opal-A zone) tend to show smaller value of $\Delta \mathrm{LF}$, which means the difference between the MDF's of ARM and IRM is smaller for the opal-A samples. It should be stressed that the grain size distribution between the sample form opal-A zone and that of quartz zone are not identical.

The correlation between $\chi_{\mathrm{ARM}}$ and $\chi$ is illustrated in Figure 7 . The lines denoted as $0.1 \mu \mathrm{m}\left(\chi_{\text {ARM }} \chi=5.43\right), 1.0 \mu \mathrm{m}\left(\chi_{\text {ARM }} \chi=2.43\right)$, and $\sim 5.0 \mu \mathrm{m}\left(\chi_{\text {ARM }} \chi=1.18\right)$ are defined after King et al. (1982). Most of data points are scattered along the line of $1.0 \mu \mathrm{m}$. If this semiquantitative grain size estimation is valid, our samples fall on the region of 
single- to two-domain of magnetite (Dunlop, 1981). Doh et al. (1988) found their nonfossiliferous pelagic clay from the North Pacific having $\chi_{\text {ARM }} \chi \chi$ ratios of 2.6 to 4.2 , almost comparable to that of our samples. Tauxe and Wu (1990), however, reported a much higher $\chi_{\text {ARM } /} \chi$ ratio of about 25 . Their samples were pelagic, carbonaceous sediments recovered from the Ontong-Java Plateau. They discussed that contribution of diagenetic material may bring the underestimation of grain size compared to the original one described by King et al. (1982). They also pointed out that the $\chi_{\text {ARM }} \chi$ ratio reported by King et al. (1982) was determined on synthetic samples of higher magnetic concentration than natural materials. Because Site 797 is situated in the Yamato Basin, surrounded by the continent and active volcanic arcs, it might be assumed that grain size distribution of our sample shifted to coarser range relative to that of pelagic sediments. The results, however, suggest that the estimated grain distribution of the magnetic minerals is almost compatible to the pelagic one.

\section{Downcore Variation of Rock Magnetic Parameters}

Among the various downcore fluctuations, intensities of ARM and IRM, and the $\chi_{\mathrm{ARM}} \chi \chi$ ratio show significant decrease in the opal-A zone as show in Figure 8. The decrease of ARM and IRM intensities may suggest diagenetic dissolution of magnetic minerals (e.g., Channell and Hawthorne, 1990). It should be noted that the $\chi_{\text {ARM } /} \chi$ ratio also decrease to one third of the value of the uppermost part. As discussed previously, the $\chi_{\text {ARM } /} \chi$ ratio is a indicator of magnetic grain size, and the decreasing implies coarsening of grains. In other word, coarsening can be explained by progressive dissolution of finer minerals. We did not find systematic downcore decrease of $\chi$. The pronouncing decrease of $\chi_{\text {ARM }} \chi \chi$ ratio is mainly brought from diagenetic loss of fine magnetic mineral which effectively carry NRM of the sediments. In the quartz zone, ARM, IRM, and the $\chi_{\text {ARM }} \chi \chi$ ratio are scattered. The progress of diagenesis and possible thermal alteration caused by igneous intrusions may have produced magnetite as explained by type $\mathrm{D}$ thermal demagnetization curve of IRM.

\section{CONCLUDING REMARKS}

1. The stability of remanent magnetization was examined by progressive AF and thermal demagnetizations. AF method is generally not effective in eliminating secondary overprinting because of easy acquisition of ARM. Thermal demagnetization is more effective in revealing a high-temperature component, but was occasionally impaired by the production of new magnetic minerals. The ratio of $\chi_{450} \chi \chi$ was a useful parameter to describe production of new magnetic minerals during the demagnetization. We could not find significant difference of $\chi_{450 /} \chi$ ratio between dark and light color layers in the APC zone.

2. Magnetic mineralogy was investigated by thermal demagnetization of three orthogonal IRM's. Unblocking temperature of the three coercivity ranges revealed that there are at least four types of magnetic mineral assemblage. In the opal-A zone, a mixture of pyrrhotite and (titano)magnetite is dominant. The mixing ratio of (titano)magnetite and pyrrhotite is changeable from sample to sample judging from the pattern of the thermal demagnetization curves. Magnetite is more dominant in the lower part of the hole (opal-CT and quartz zones).

3. Apparent grain size of the magnetic minerals were estimated by the Lowrie-Fuller test and by using the $\chi_{\text {ARM }} \chi$ ratio. We pointed out that magnetic minerals of most samples from Site 797 are of SD/PSD or small MD size, and resemble that of normal deep-sea sediments such as from the South Atlantic (Petersen et al., 1986), the Northeast Pacific (Karlin, 1990b), and the North Pacific (Doh et al., 1988). Magnetic mineralogy and grain size distribution are not identical in the opal-A zone and in the quartz zone. The $\Delta L F$ values make separate clusters when plotted against MDF of IRM and/or remanent acquisition coercivity.
4. Some rock magnetic parameters such as ARM and IRM intensities, and the $\chi_{\text {ARM }} \chi$ ratio showed characteristic downcore decrease within the opal-A zone. This fact implies diagenetic dissolution of finer magnetic minerals in the sediments. In the lower part of the hole, production of magnetic minerals is suggested. The intrusion of igneous rocks might accelerate production of magnetite. Paleomagnetic directions might have been safely preserved in the upper part of opal-A zone, but severely overprinted in the quartz zone.

\section{ACKNOWLEDGMENTS}

We thank the crew and the shipboard technical and scientific parties of Leg 127, and co-chief scientists, K. Tamaki and K. Pisciotto. We also thank K. Fukuma for useful discussions. Editorial comments by $\mathrm{M}$. McWilliams and detailed and constructive reviews by $\mathrm{K}$. P. Kodama and J. W. King significantly improved the manuscript. We thank R. Arai for her help in improving the manuscript. This work was partly supported by a Grant-in-aid for scientific research of Ministry of Education of Japan (No. 01540628).

\section{REFERENCES}

Banerjee, S., King, J., and Marvin, J., 1981. A rapid method for magnetic granulometry with application to environmental studies. Geophys. Res. Lett., 8:333-336.

Channell, J.E.T., and Hawthorne, T., 1990. Progressive dissolution of titanomagnetites at ODP Site 653 (Tyrrhenian Sea). Earth Planet. Sci. Lett., 96:469-480.

Doh, S. J., King, J. W., and Leinen, M., 1988. A rock-magnetic study of giant piston core LL4-GPC3 from the central North Pacific and its paleoceanographic implication. Paleoceanography, 3:89-1113.

Dunlop, D. J., 1981. The rock magnetism of fine particles. Phys. Earth Planet. Inter., 26:1-26.

Johnson, H. P., Lowrie, W., and Kent, D. V., 1975. Stability of anhysteretic remanent magnetization in fine and coarse magnetite and maghemite particles. Geophys. J. R. Astron. Soc., 41:1-10.

Karig, D. E., Ingle, J. C., Jr., et al., 1975. Init. Repts. DSDP, 31: Washington (U.S. Govt. Printing Office).

Karlin, R., 1990a. Magnetic diagenesis in marine sediments from the Oregon continental margin. J. Geophys. Res., 95:4405-4419.

1990b. Magnetic mineral diagenesis in suboxic sediments at Bettis Site W-S, NE Pacific Ocean. J. Geophys. Res., 95:4421-4436.

King, J. W., Banerjee, S. K., Marvin, J., and Özdemir, Ö., 1982. A comparison of different magnetic methods for determining the relative grain size of magnetite in natural materials: some results from lake sediments. Earth Planet. Sci. Lett., 59:404-419.

King, J. W., and Channell, J.E.T., 1991. Sedimentary magnetism, environmental magnetism, and magnetostratigraphy. Rev. Geophys., Suppl., 358-370.

Kobayashi, K., and Nomura, M., 1972. Iron sulfides in the sediments cores from the Sea of Japan and their geophysical implications. Earth Planet. Sci. Lett., 16:200-208.

Lowrie, W., 1990. Identification of ferromagnetic minerals in a rock by coercivity and unblocking temperature properties. Geophys. Res. Lett., 17:159-162.

O'Reilly, W., 1984. Rock and Mineral Magnetism: Glasgow (Blackie).

Petersen, N., von Dobeneck, T., and Vali, H., 1986. Fossil bacterial magnetite in deep-sea sediments from the South Atlantic Ocean. Nature, 320:611-615.

Tada, R., 1991. Compaction and cementation in siliceous rocks and their possible effect on bedding enhancement. In Einsele, G., Ricken, W., and Seilacher, A. (Eds.), Cycle and Event in Stratigraphy. Heidelberg (Springer), 480-491.

Tamaki, K., Pisciotto, K., Allan, J., et al., 1990. Proc. ODP, Init. Repts., 127: College Station, TX (Ocean Drilling Program).

Tauxe, L., and Wu, G., 1990. Normalized remanence in sediments of the Western Equatorial Pacific: relative paleointensity of the geomagnetic field? J. Geophys. Res., 95:12337-12350.

Yamazaki, T., and Katsura, I., 1990. Magnetic grain size and viscous remanent magnetization of pelagic clay. J. Geophys. Res., 95:4373-4382.

Zijderveld, J.D.A., 1967. AC demagnetization of rocks: analysis of results. In Collinson, D. W., Creer, K. M., and Runcorn, S. K. (Eds.), Methods in Paleomagnetism: Amsterdam (Elsevier), 255-286.

Date of initial receipt: 18 March 1991

Date of acceptance: 10 February 1992

Ms 127/128B-213 


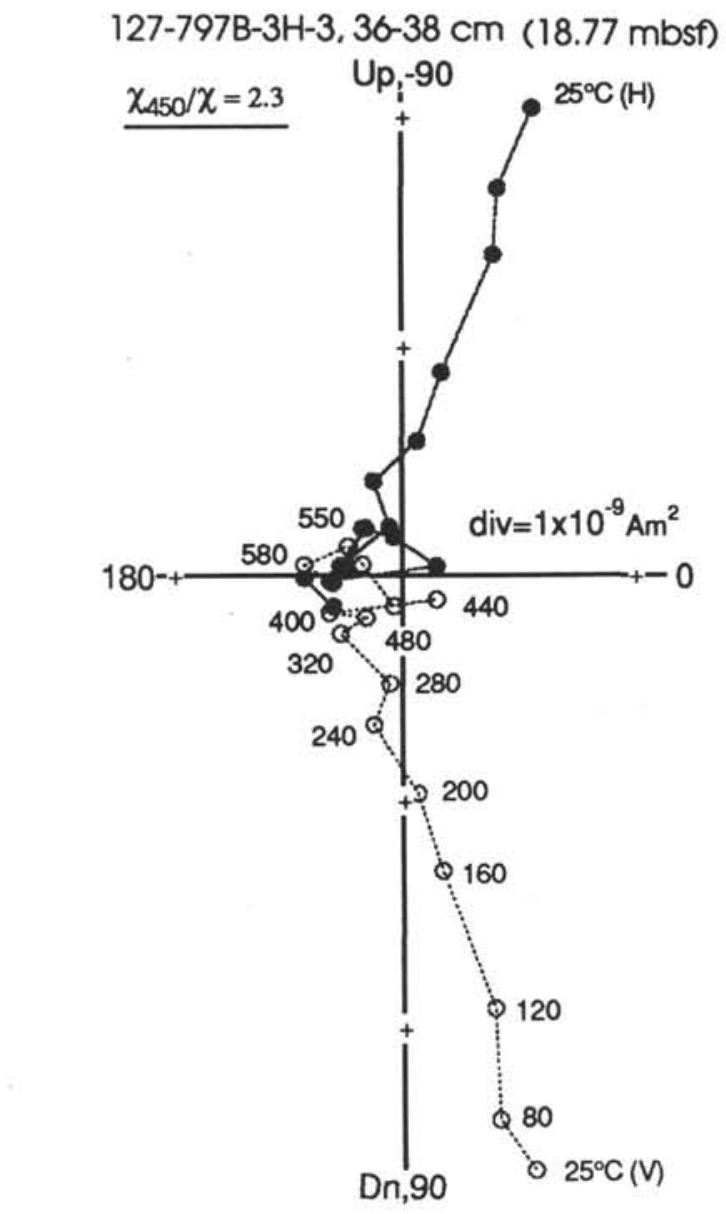

127-797B-4H-3, 144-146 cm (29.35 mbsf)

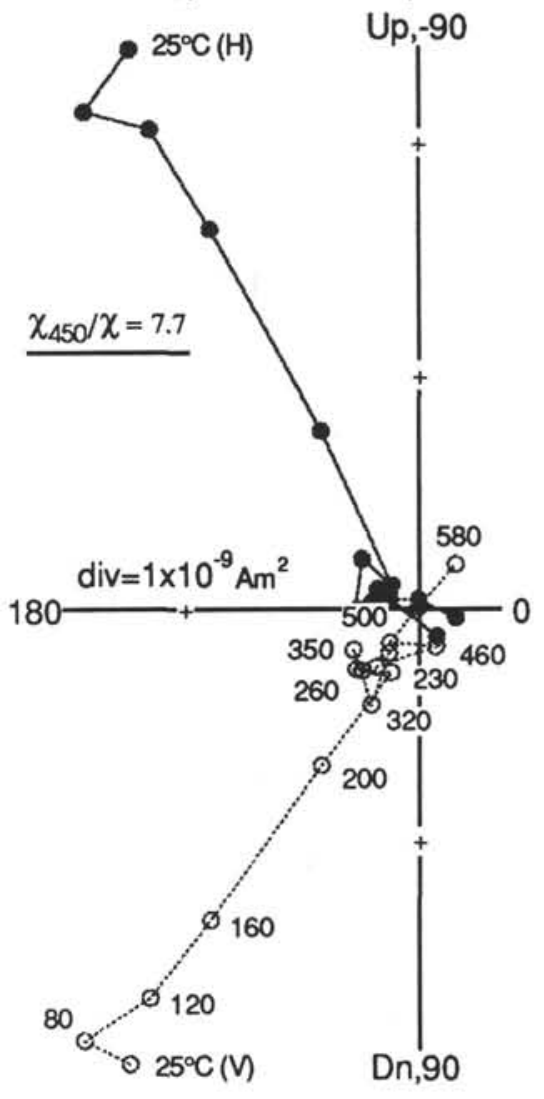

$127-797 \mathrm{~B}-5 \mathrm{H}-5,140-142 \mathrm{~cm}(41.81 \mathrm{mbsf})$

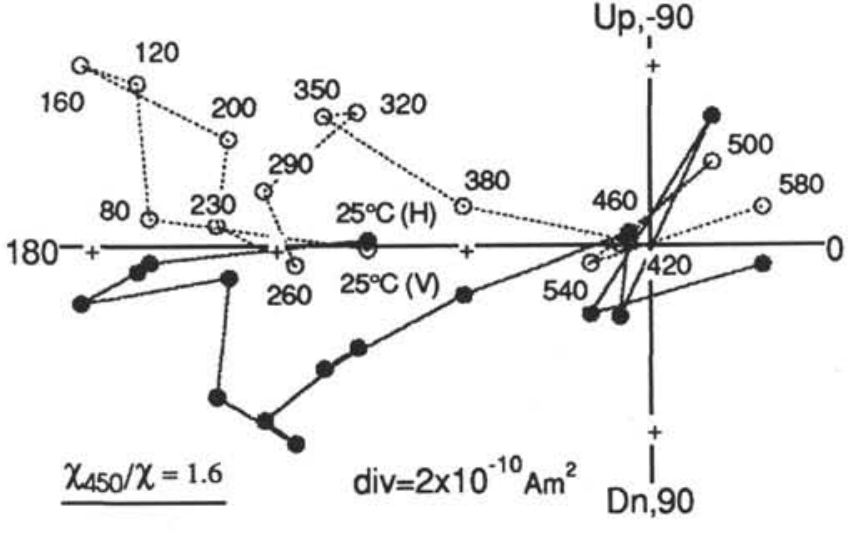

$127-797 \mathrm{~B}-6 \mathrm{H}-5,83-85 \mathrm{~cm}(50.74 \mathrm{mbs})$

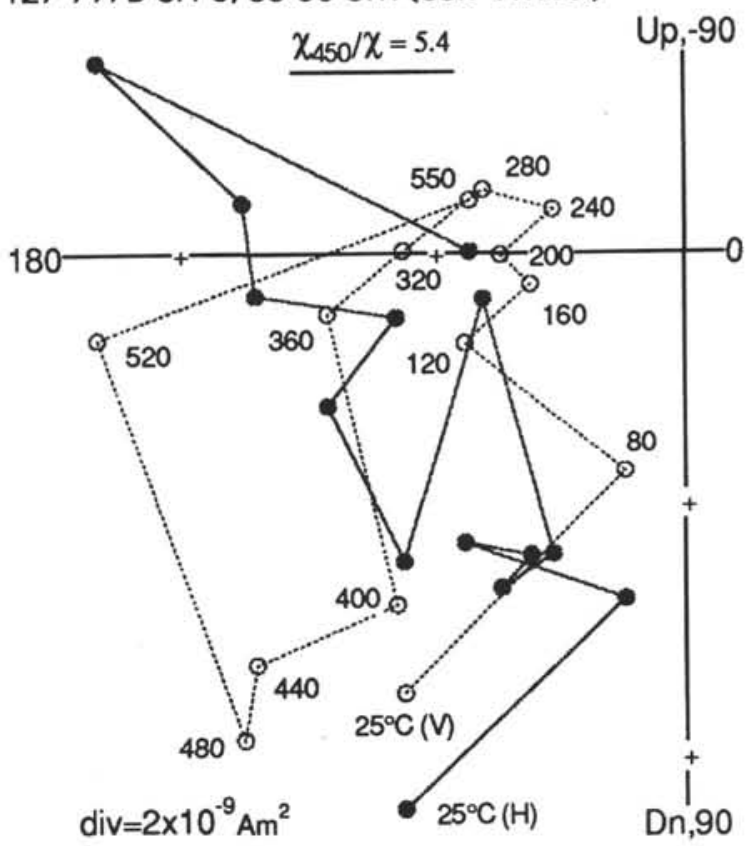

Figure 2. Examples of vector-demagnetization diagrams of stepwise thermal demagnetization data. The demagnetization temperature in degree Celsius are indicated for each point. $\chi_{450 / \chi}$ indicates ratio of initial susceptibility measured after heating up to $450^{\circ} \mathrm{C}$ to the value before demagnetization. Symbols as for Figure 1 . 
127-797B-8H-5, 90-92 cm (69.81 mbsf)
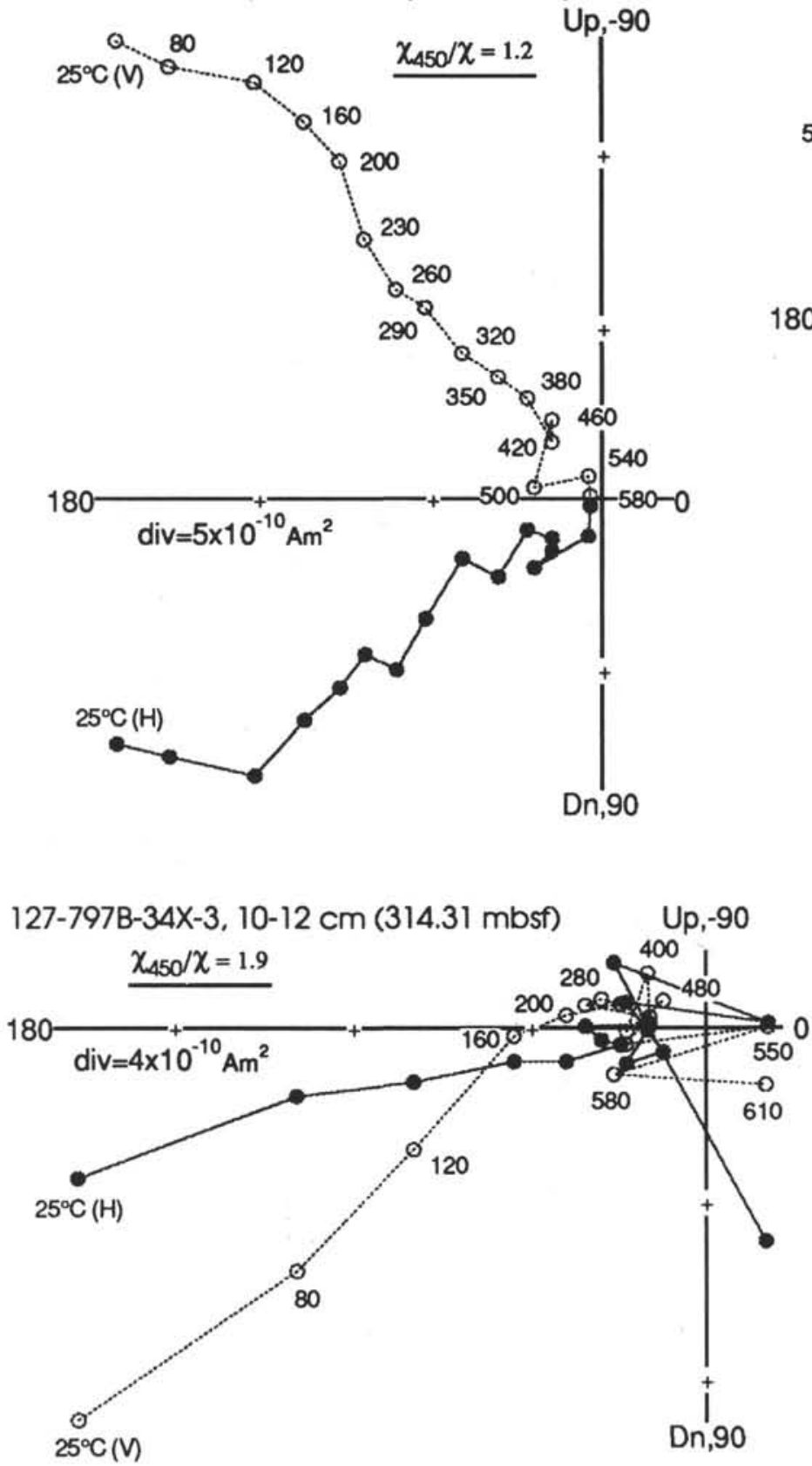

127-797B-12H-3, $64-66 \mathrm{~cm}$ (104.55 mbsf)

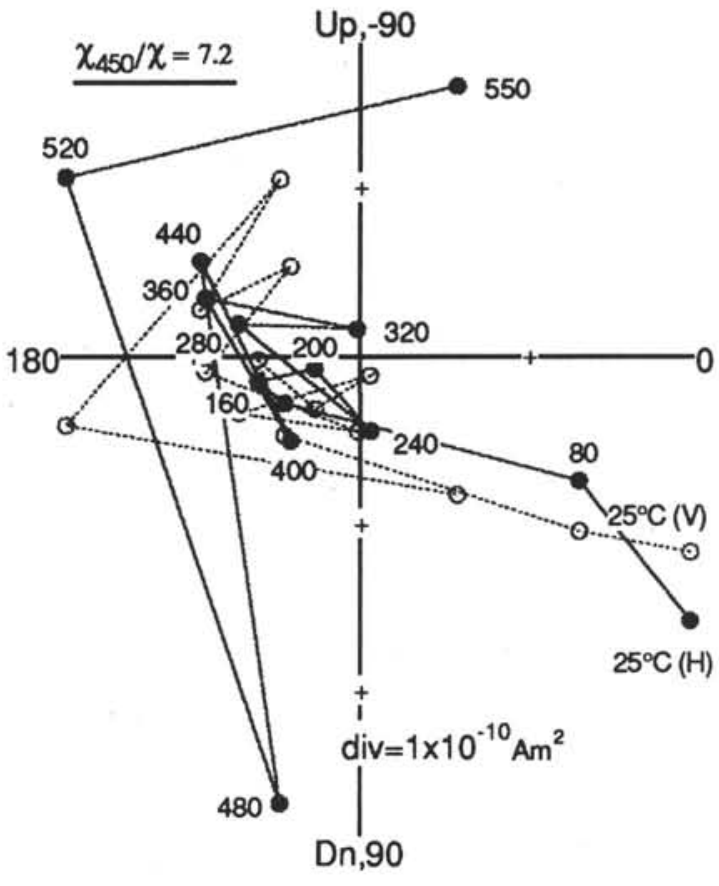

$127-797 \mathrm{C}-6 \mathrm{R}-3,56-58 \mathrm{~cm}(535.17 \mathrm{mbsf})$

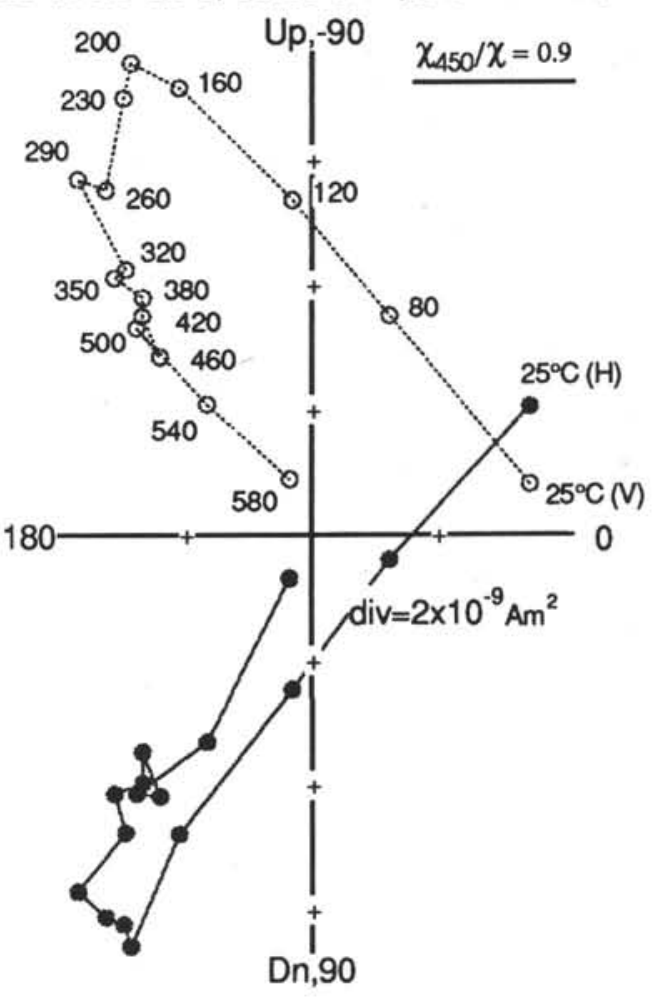

Figure 2 (continued). 

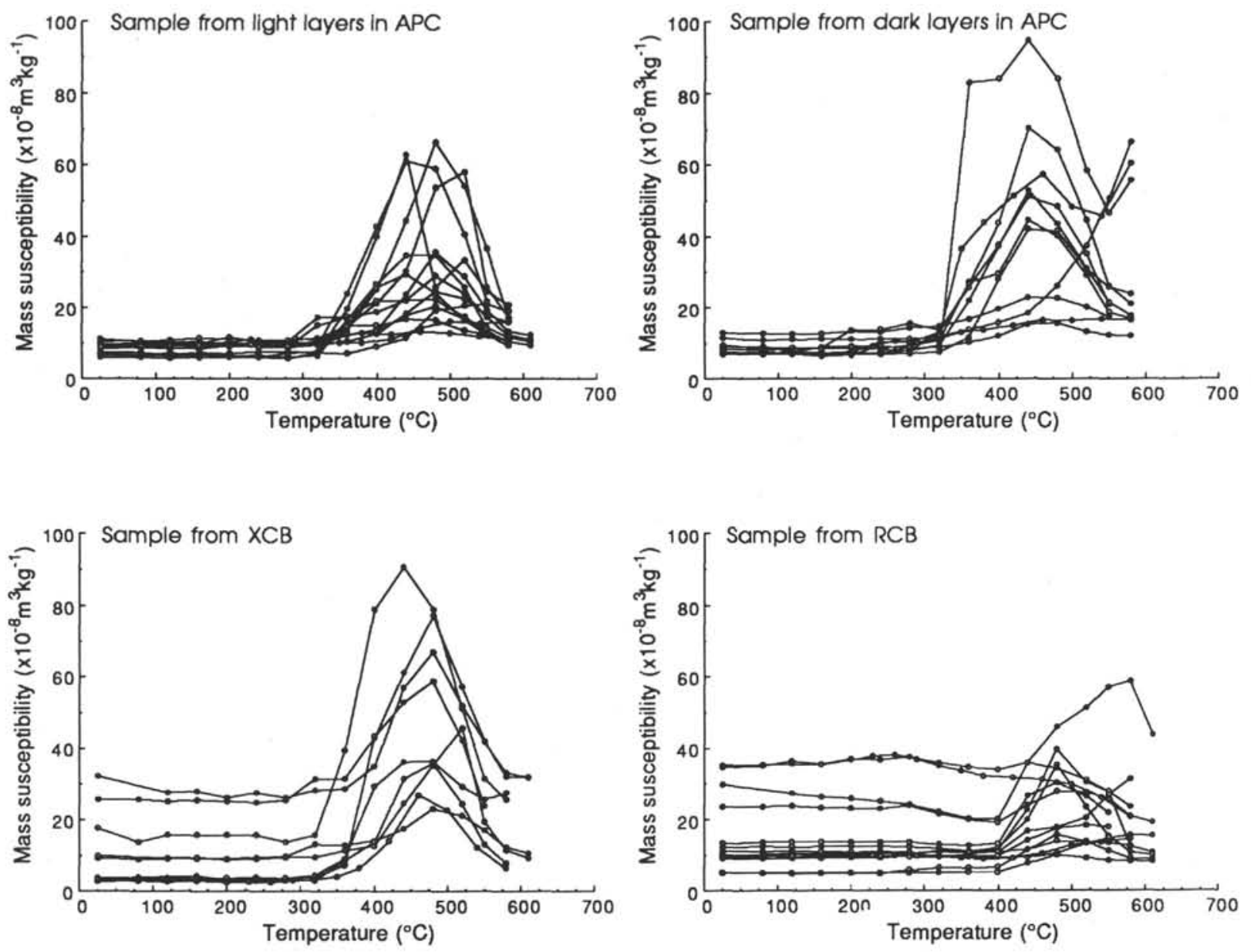

Figure 3. Mass initial susceptibility $(\chi)$ measured after each step of thermal demagnetizations. Increases of $\chi$ at about $400^{\circ}-500^{\circ} \mathrm{C}$ are observed for most of samples.

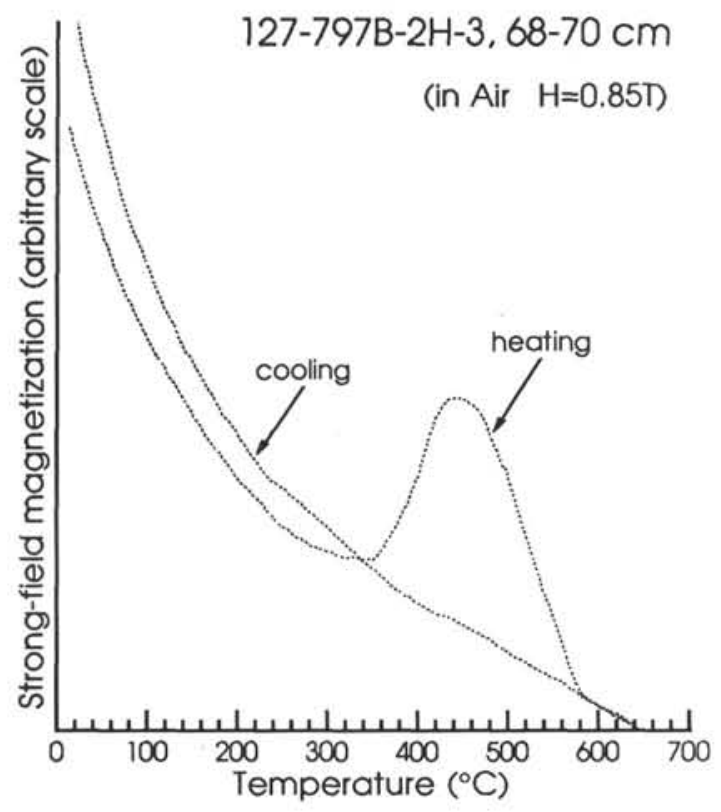

Figure 4. Example of thermomagnetic analysis of bulk sample in air (127-797B-2H-3, 68-70 cm). 

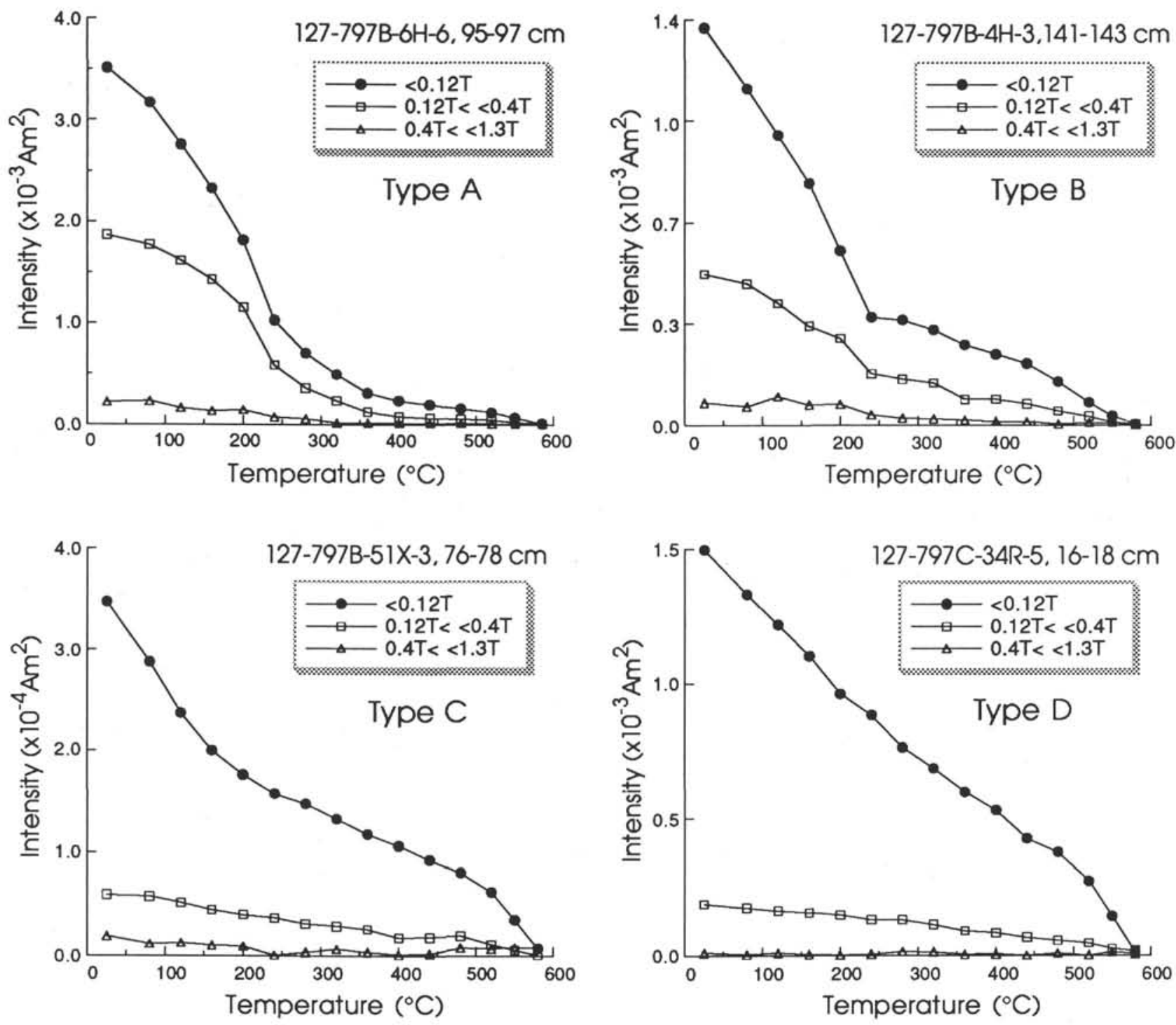

Figure 5. Four types of thermal demagnetization curves of orthogonal IRM's (type A to D). Closed circles indicate thermal decay of IRM intensity imparted by the field of $0.1 \mathrm{~T}$. Open squares and open triangles indicate demagnetization curves of medium $(0.4-1.3 \mathrm{~T})$ and hard $(1.3 \mathrm{~T}) \mathrm{IRM}$ 's, respectively. 

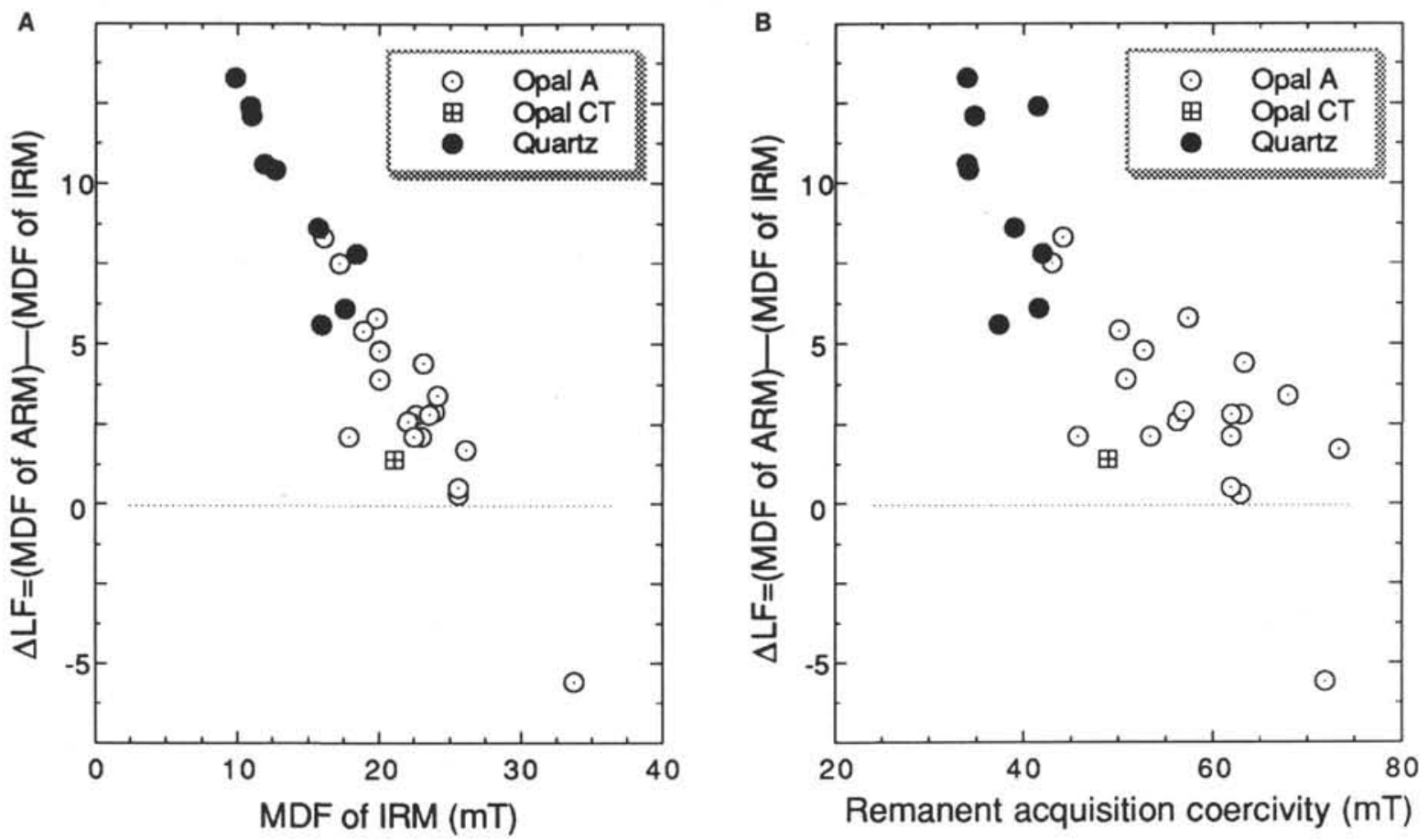

Figure 6. A. Plot of $\triangle \mathrm{LF}$ (= MDF of ARM - MDF of IRM) vs. MDF of IRM. B. Plot of $\triangle \mathrm{LF}$ vs. remanent acquisition coercivity (Bcr).

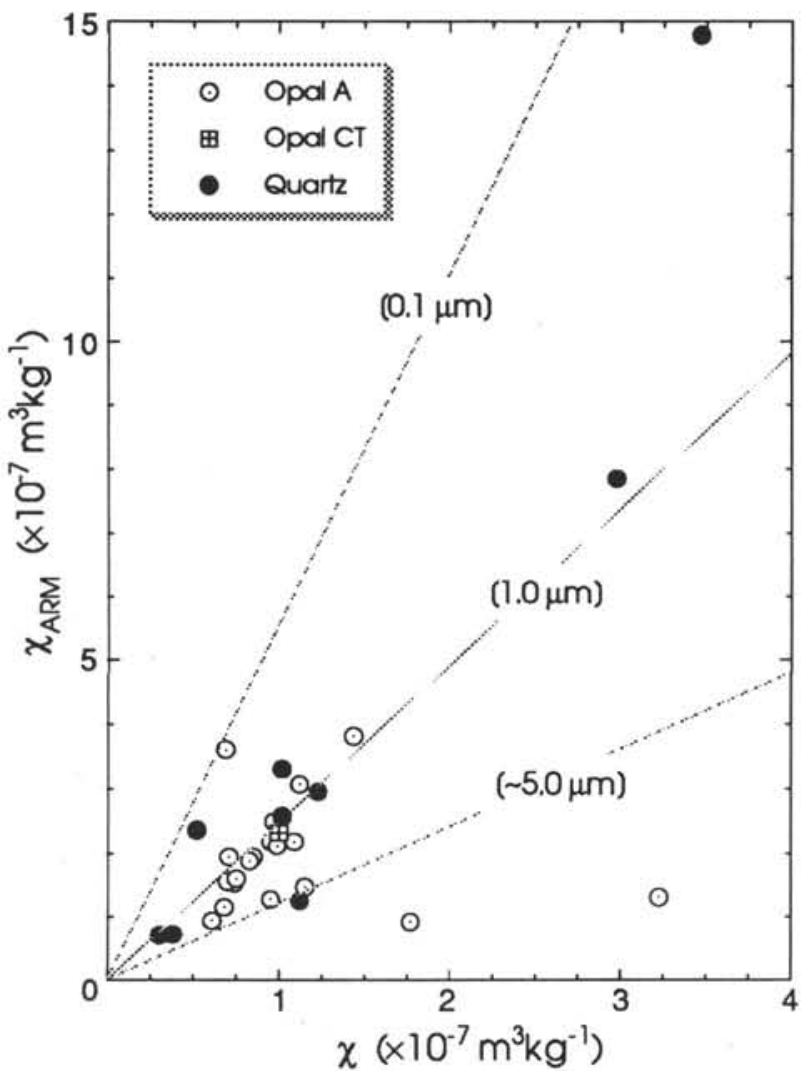

Figure 7. Plot of mass susceptibility of ARM $\left(\chi_{\text {ARM }}\right)$ against mass initial susceptibility $(\chi)$. Lines denoted $0.1 \mu \mathrm{m}$ to $\sim 5.0 \mu \mathrm{m}$ are defined after King et al. (1982). 

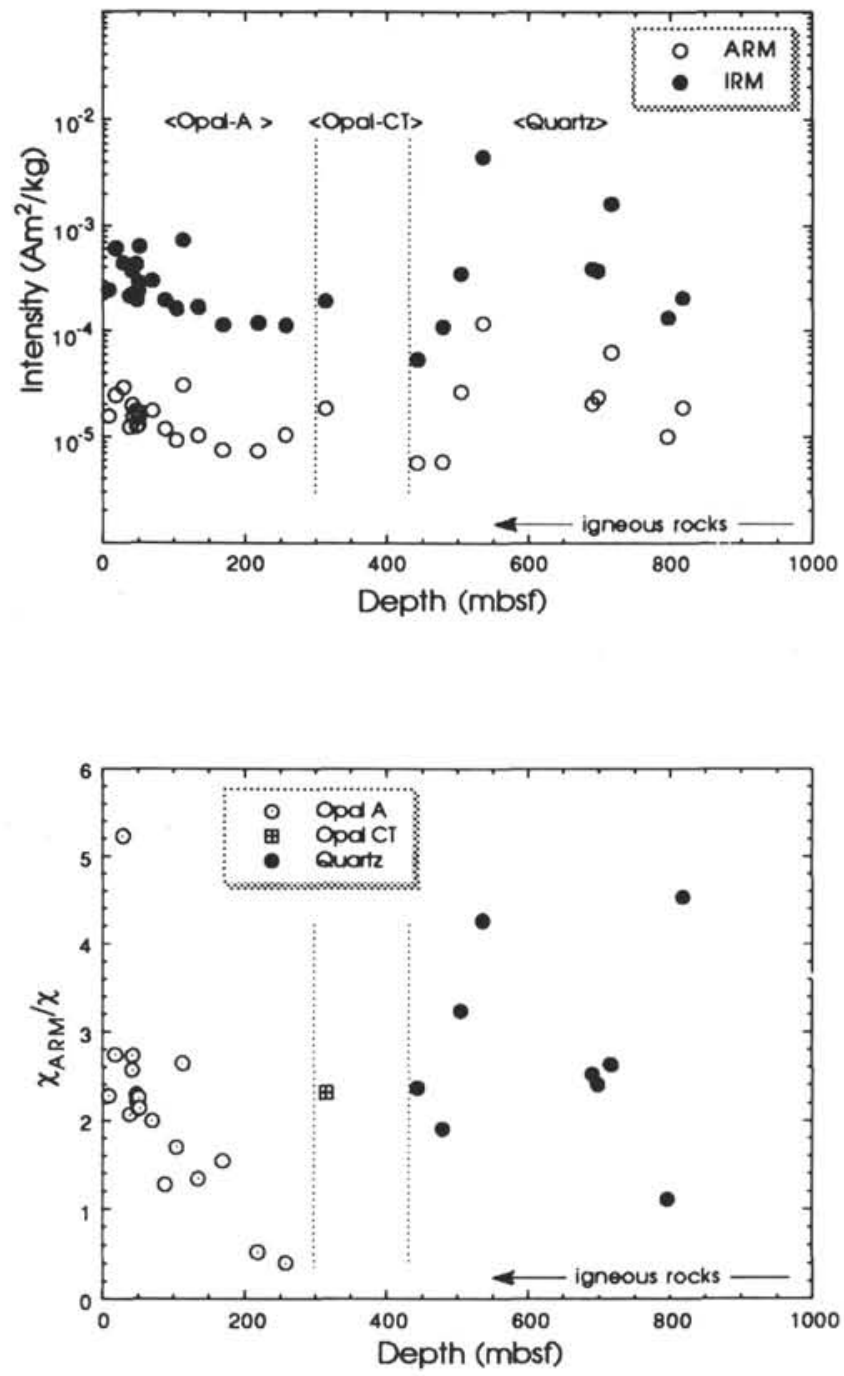

Figure 8. Downcore plot of ARM and IRM intensities (above), and $\chi_{\text {ARM }} / \chi$ ratio (below). 